\title{
CHRONIC NONSPECIFIC TENOSYNOVITIS OF FLEXOR TENDON SHEATH (WITH RICE BODIES) IN THE HAND- TEN YEARS FOLLOW UP.
}

\begin{tabular}{ll} 
Dr. K. Anji Reddy* & Director, Consultant Plastic Surgery * Corresponding Author \\
\hline $\begin{array}{l}\text { Dr. A. Anjana } \\
\text { priyanka }\end{array}$ & Assistant professor, department- pathology Asram medical college. \\
\hline Dr. Gudeli Vahini & Professor, department-pathology, Asram medical college \\
\hline Dr. R. Harshini & Post Graduate, Department- Pathology, Asram Medical College \\
\hline \hline
\end{tabular}

ABSTRACT Rice bodies are fibrous bodies resembling grains of rice. They are associated with many inflammatory conditions like rheumatoid arthritis, tuberculosis, juvenile arthritides, seronegative arthritis, osteoarthritis, septic joints and chronic bursitis. Rice bodies are seen in pleural fluid, in the setting of bursitis and within the tendon sheath. We describe a rare case of Rice body tenosynovitis of flexor tendon sheath of a finger in a hand that showed no evidence of any infection or rheumatic disease after repetitive diagnostic procedures.

Case presentation: We report a case of forty-nine-year-old fisherman presenting with progressive, painless sausage shaped swelling of right hand middle finger for two years.

Discussion: Rice bodies are formed in inflammatory joint diseases and mostly with tuberculous etiology but rarely found in non-tuberculous patient. This is a case of Rice body formation associated with chronic Nonspecific tenosynovitis of middle finger right hand. Conclusion: Rice bodies in the distal palm to digital flexor tendon sheath of Right-hand middle finger with no specific etiology are extremely rare clinical Presentation. MRI, radiography and histopathology were useful in arriving at a Diagnosis. Over the period of 10 years, only one flexor tendon sheath of right hand middle finger was affected, without any other disability. Since his occupation is fishing, may be bite of the fish may be a reason. This chronic inflammation of the middle finger tendon sheath of the flexor tendon was confined only to that finger over the past 10 years. Now after complete excision of the sheath, he is free of this problem and is able to continue his profession without any difficulty.

KEYWORDS : Rice bodies, non specific, tenosynovitis, rheumatoid arthritis, bursitis, magnetic resonance imaging ultrasound.

INTRODUCTION

Rice bodies are floating rice like particles in synovial space could be found in the inflammatory joint diseases. They were first described and reported by Reise in 1895 in Tuberculosis arthritis. Rice body formation is also associated with multiple inflammatory conditions such as chronic arthritides, Rheumatoid arthritis, infection and sometimes trauma ${ }^{(1-2)}$ Rice bodies resemble melon seeds and millet seeds. There are different sites of rice body formation which have been reported such as knee, shoulder, extensor tendon in the hand, wrist, carpal tunnel and flexor tendon sheath. Rice bodies are also seen in pleural fluid, within bursae and the tendon sheath $^{(1)}$.The histopathological examination reveals only fibrin, and, in some cases, collagenous nucleus surrounded by a fibrin layer ${ }^{(1)}$. The diagnostic modalities useful are ultrasound, magnetic resonance imaging (MRI) and plain radiography. There are several concepts involved in rice bodies formation which include microvascular infarcts in the joint synovium after sloughing off enmesh in fibrin layers. Another concept is activation of the fibroblasts leading to collagen formation which later encased in fibrin layers. We have a rare case of rice bodies in digital flexor tendon which is not associated with inflammatory disease such as mycobacterial infection or rheumatoid arthritis. The investigating aides such as magnetic resonance imaging (MRI), ultrasound and radiography (plain X-Ray) helped in arriving at correct diagnosis.

\section{Case presentation}

A forty nine year old fisherman presented with progressive sausage shaped painless swelling of right hand middle finger extending from mid palmar region to crease of distal interphalangeal joint since two years . He had no history of fever or systemic symptoms. He was earlier operated during the year 2009 at NRI hospital for trigger finger. The patient was referred to plastic surgery department at NRI hospital during the year 2009, when he was 38 years old. He was unable to completely flex or extend the middle finger of the right hand (fig 1A). On examination the flexor tendon sheath was cord like and thick (fig .1 B, 1C). Excision of the sheath was done through crease incision (fig.l D). He had free movement of the finger. He came again in the year 2019 at the age of 49 years with restricted movements of the same (right-hand middle finger) and a localised subcutaneous swelling extending from the proximal palmar crease to the distal interphalangeal joint of right middle finger(fig .2A, 2B). The swelling was $7 \mathrm{~cm} \mathrm{x} 4 \mathrm{~cm}$ in size, soft, cystic with fluctuation (fig.2B). The overlying skin was stretched, but normal except at the proximal volar digital crease where it was thinned out. He is not having any other health problem except for his going for fishing occupation regularly. At the time of first visit with trigger finger in the year 2009, we operated from thickened flexor tendon sheath of the middle finger which was excised and he had free movements after that. When we operated during the year 2019 where he came with swelling of the lesion confined only to the flexor digital sheath of the middle finger with thick sac or fluid collection extending from the level of distal palmar crease to the distal interphalangeal joint of the middle finger (Fig.3A, B). In spite of the size, long duration and earlier surgical intervention the lesion was confined only to the digital tendon sheath. Even the underlying tendons are normal and no evidence of any spread of the pathology to any of the other finger (fig 3D). It only shows that it is not of infective etiology. It is probably due to fish bite, a prick in the palm, that caused inflammation within the sheath, and that continued chronically. It is very interesting to note that it is purely non specific and localized. MRI of right hand revealed specific ovoid shaped nodule with altered signal intensity area which is heterogeneously hyperintense on $\mathrm{Tl} / \mathrm{T} 2$ images noted adjacent to flexor tendon of middle finger extending from distal half of palm up to middle phalanx on the ventral aspect (Fig 2D). Histopathological sections show fibrocollagenous tissue with synovial lining arranged in papillary fronds and subepithelium with inflammatory cell collections of lymphocytes, plasma cells, neutrophils and macrophages. The surface shows structures with amorphous eosinophilic 
core surrounded by a layer of fibrin (Rice bodies) (Fig 4D). One of the sections shows positivity for Von kossa stain indicating calcium crystals. Differential diagnosis were chronic fungal infection, atypical mycobacterium Infection, sarcoidosis, systemic lupus erythematosus and pigmented villonodular synovitis. The negative bacterial and fungal cultures and laboratory test results along with absence of suggestive complications excluded these conditions. Definitive treatment included radical excision of the mass through crease incision on May $7^{\text {th }}$ 2019. The postoperative course was uneventful except for mild inflammation at the incision site. It was resolved with antibiotics and the patient showed full range of motion and normal sensory capacity after surgery in three weeks.

Post operative photograph on November $4^{\text {th }} 2019$ shows normal range of movements of all the fingers right hand (6 months follow up) (Fig 5.A, B,C,D)

\section{PHOTOGRAPHS}

\section{TEN YEARS BACK $(5 / 11 / 2009)$}

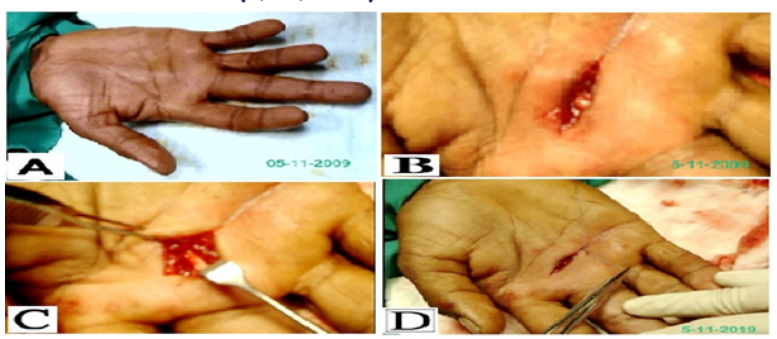

FIGURE 1 ( $A, B, C, D)$

FIG 1 A, B. Thickened flexor tendon sheath right hand in the palm extending to the middle finger $\mathrm{l} \mathrm{C}$. Flexor tendon sheath thick, cord like, l D. Excision of the thickened flexor tendon sheath through crease incision

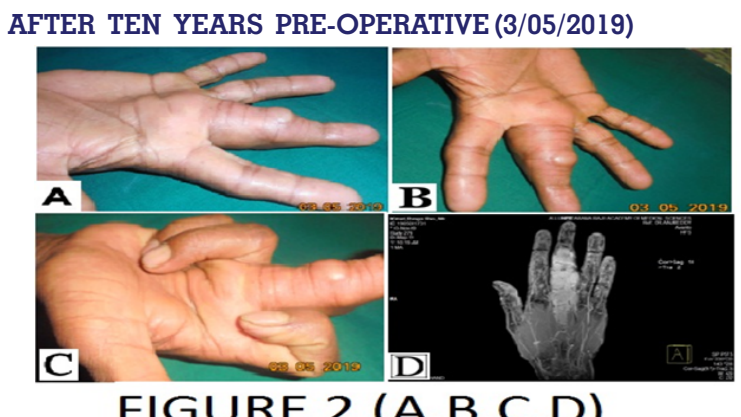

2 A, B - Swelling from proximal palmar crease to distal interphalangeal Joint of middle finger, swelling soft, cystic, confined to flexor digital sheath of middle finger C- Trigger finger D- MRI shows hyper intense specific ovoid shaped nodule

\section{AFTER TEN YEARS PER-OPERATIVE}

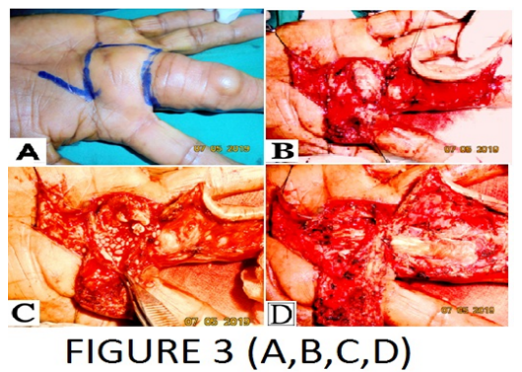

3A .Skin incision B .Flexor tendon sheath opened with thick sac and fluid collection C. With Rice Bodies D. Flexor tendons after complete excision of sheath

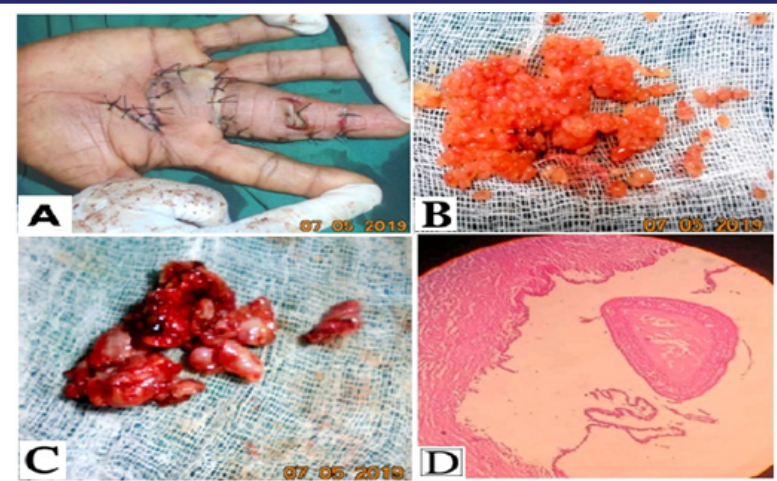

FIGURE $4(A, B, C, D)$

4 A. Post operative photo of right hand B, C. Gross appearance of Rice bodies resembling Melon/millet seeds D. Microphotograph of haematoxylin and eosin stained section, Magnification power X 40, showing structure with Amorphous eosinophilic core surrounded by a layer fibrin material - RICEBODY.

\section{POST -OPERATIVE AFTER SIX MONTHS}

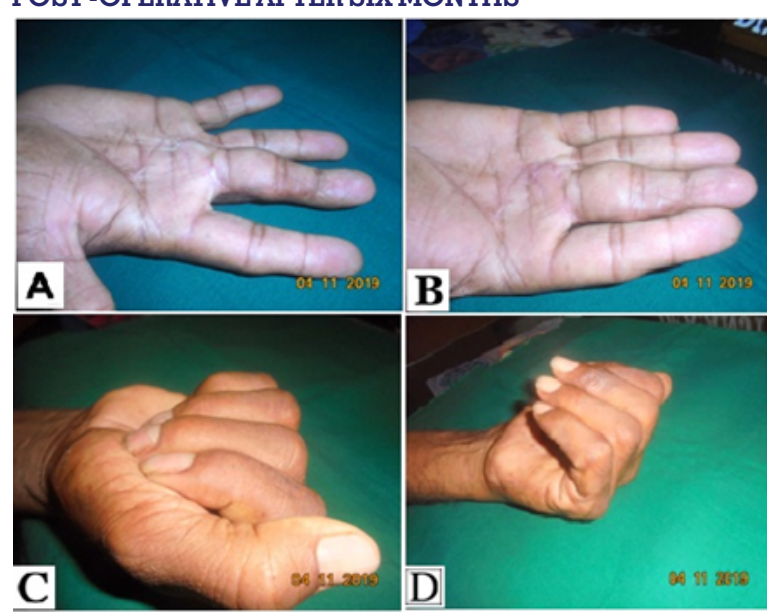

FIGURE $5(A, B, C, D)$

Fig 5 . A, B, C, D- Showing normal fingers with complete range of movements

\section{DISCUSSION}

Riese in the year 1895 first described a case of rice body formation in association with Tuberculosis ${ }^{(1)}$. The incidence of its formation is less than $50 \%$ in cases of tuberculous tenosynovitis and their presence in the joint fluid of patients with rheumatoid arthritis may be more common than hitherto suspected $^{(2)}$.

Rice bodies are the particles that have a cartilage like shiny appearance and are of synovial origin, composed of collagen and calcium salts ( calcium apatite, calcium phosphate, calcium pyrophosphate dehydrate crystals $)^{(3)}$.They develop as a non specific response to synovial inflammation and ischemia, caused by Rheumatoid arthritis, Tuberculous arthritis, seronegative arthritis and bursitis ${ }^{(3)}$.There are several theories associated which include synovial proliferation and hypertrophy in joint space with synovial cells undergoing infarction and shedding into joint and later encased by fibronectin ${ }^{(4)}$ Also fibrin accumulates in the villous structures of the hypertrophied synovium causing them to elongate and snap off.

Rice bodies are rare incidental finding in synovial space, bursa, around tendon sheaths, as well as in pleural fluid of 
patients with Rheumatoid arthritis ${ }^{(5)}$ Cheung et al. suggested that rice bodies arise from infarcted synovial cells and which are shed into the bursal fluid ${ }^{(6)}$ Berg et al. suggested, in an electron microscopy study of rice bodies obtained from the joints of rheumatoid arthritis patients, that non-vascularised rice bodies might have formed de novo as part of an inflammatory reaction in the synovial fluid ${ }^{(7)}$

Nagasawa et al. reported a case of a 68 year old man with rice body formation in the flexor tendon of fingers without any history of inflammatory disease ${ }^{(8)}$ Muirhead et al. reported a case of a 9-year-old boy with rice bodies in the tendon sheath of the right tibialis posterior tendon subsequent to a thorn injury ${ }^{(9)}$. And Sugano reported an 81 - year- old man with rice bodies in the common flexor synovial sheath of the left wrist

${ }^{(10)}$ In all these cases, rheumatoid factor was negative and patients had no history of tuberculosis, similar to in our case.

Many authors have done lot of study on the nature of rice bodies. Albrecht et al. suggested fibrous rice bodies represent an end product of synovial inflammation, proliferation and subsequent secondary degeneration ${ }^{(11)}$.

The important differential diagnoses also include pigmented villonodular synovitis and synovial chondromatosis in patients with rice bodies. MRI shows hypointense loose bodies on all sequences with low signal on T2 weighted and proton density weighted images making it possible to make an accurate diagnosis of rice bodies ${ }^{(12,13,14)}$ The lack of susceptibility artefact in rice bodies on gradient echosequences helps to distinguish them from pigmented villonodular synovitis ${ }^{(14)}$.

\section{CONCLUSION-}

Rice bodies formations are rare clinical presentation. They are usually seen in multiple inflammatory conditions but extremely rare with non specific etiology. We followed the patient over the last ten years, (2009 to 2019). This type of the case with chronic nonspecific tenosynovitis and cystic swelling with rice bodies in a forty nine year old male involving the flexor tendon of the hand is unique in literature. The total excision of the sheath, gave him good relief and he is going to his profession without any disability.

\section{ACKNOWLEDGMENTS:}

We are thankful to the department of pathology and Radioimaging of Asram medical college for excellent cooperation in Radioimaging of the hand and histopathology study.

\section{REFERENCES}

1. Rice body formation without rheumatic disease or tuberculosis infection: $\alpha$ case report and literature review. Forse CL, Muscha BL, Santos ML, Ongcapin EH. Clin Rheumatol.2012; 31:1753-1756.

2. Subacromial bursitis with rice bodies as the presenting manifestation of rheumatoid arthritis. Kataria RK, Chaiamnuay S, Jacobson LD, Brent LH. J Rheumatol.2003; 30:1354-1355.

3. Sagger: RM, Gregg Smith. SJ. Imaging of Rice-bodies in a non-rheumatoid shoulder. JRheumatol.2007:46:64-69.

4. Matsumoto K, Fujitha K, Fujiko H, Matsushima S, Kouso K, Yamaguchi S, Kurosaka M, Yoshiya S. Massive nonspecific olecranon bursitis with multiple rice bodies. J Shoulder Elbow Surg 2004; 13: 680-83.

5. Kassimos D, George E, Kirwan JR. Rice bodies in pleural aspirate of patient with rheumatoid arthritis. Ann Rheum Dis 2004; 53:427-8.

6. Asik M., Eralp L., Cetik O., Altinel L. Rice bodies of synovial origin in the knee joint. Arthroscopy. 2001; 17:El.

7. Berg E., Wainwright R., Barton B., Puchtler H., McDonald T. On the nature of rheumatoid rice bodies; an immunological, histochemical and electron microscopy study. Arthritis Rheum. 1977; 20: 1343-9.

8. Nagasawa H., Okada K., Senma S., Chida S.' Shimada Y. Tenosynovitis with rice body formation in a non tuberculosis patient: a case report. Ups.j. Med. Sci 2009; 114; 184-188.

9. Muirhead D.E., Johnson E., H., luis C. A light and ultrastructural study of rice bodies recovered from a case of thorn induced extra-articular synovitis. Ultrastruct. Pathol; 22;341-347.

10. Sugano H., Nagao T., Tajima Y., Ishida Y., Nagao K., Ohno T. Variation among giant rice bodies; report of four cases and their clinicopathological features. Skeletal Radiol.2000; 29: 525-529.

11. Albrecht M., Marinetti G.V., Jacox R.F., Vaughan J.H. A biochemical and electron microscopy study of rice body from rheumatoid patients. Arthritis Rheum.1965;8: 1053-1063.
12. Paolini G, Longo B, Laporta R, el al. Permanent latissimus dorsi muscle denervation in breast reconstruction. Ann Plast Surg 2013; 71:639-42.

13. Rapitz JM, Martin SM, Vilamajo IR, Pons JT, Androver PA. Subacromia bursitis with rice bodies. Journal of orthopaedics 2007; 4(4).

14. Spence LD, Adams J, Gibbons D, Mason MD, Eustace S. Rice body formation in bicipitoradial bursitis: ultrasound, CT and MRI findings. Skeletal Radiol 1998; 27:30-32. 